\title{
Behavioral Risk Factors for HIV Infection in Hospitalized Persons Who Co-use Stimulants and Opioids
}

\author{
Raagini Jawa ${ }^{1,6}$ - Michael D. Stein ${ }^{2,3} \cdot$ Bradley Anderson $^{3} \cdot$ Jane M. Liebschutz ${ }^{4} \cdot$ Catherine Stewart $^{2}$. \\ Kristina T. Phillips ${ }^{5}$. Joshua A. Barocas ${ }^{1,6}$
}

Accepted: 1 September 2021 / Published online: 12 September 2021

(c) The Author(s), under exclusive licence to Springer Science+Business Media, LLC, part of Springer Nature 2021

\begin{abstract}
We investigated the association of 90-day opioid and stimulant co-use and HIV risk behaviors in a cross-sectional analysis of hospitalized HIV-negative people who inject drugs (PWID). We compared those injecting opioids alone to two sub-groups who co-used opioids with (1) cocaine, (2) amphetamine-type stimulants (ATS), on sex and injection drug risk behaviors assessed via the Risk Assessment Battery (RAB), where a higher score indicates a higher risk. Of 197 participants who injected opioids, 53\% co-used cocaine only, $5 \%$ co-used ATS only, $18 \%$ co-used both cocaine and ATS, $24 \%$ co-used neither stimulant. PWID who injected opioids alone had a mean RAB drug risk score of 5.98 points and sex risk score of 2.16 points. Compared to PWID who injected opioids alone, PWID who co-used stimulants had higher mean drug risk RAB scores: cocaine, $b=2.84$ points [95\% confidence interval (CI) $1.01 ; 4.67$ ]; ATS, $b=3.43$ points (95\% CI $1.29 ; 5.57$ ). Compared to PWID who injected opioids alone, cocaine co-use was associated with higher sex RAB scores $b=1.06$ points $(95 \% \mathrm{CI}$ $0.32 ; 1.79)$. Overall, we found a significant association between stimulant co-use and higher HIV sex and drug risk scores.
\end{abstract}

Keywords HIV $\cdot$ Stimulant use $\cdot$ Opioid use $\cdot$ People who inject drugs $\cdot$ HIV risk behaviors

\section{Resumen}

Investigamos la asociación entre el uso conjunto de opioides y estimulantes durante 90 días y las conductas de riesgo frente al VIH en un análisis transversal de personas hospitalizadas que se inyectan drogas y que son VIH negativas ("PWID" en lo sucesivo). Se comparó a los que consumían únicamente opioides con dos subgrupos que consumían opioides junto con (1) cocaína, (2) estimulantes de tipo anfetamínico ("ATS" en lo sucesivo), en relación con las conductas de riesgo evaluadas mediante la Serie de Pruebas de Evaluación de Riesgos ("RAB" en lo sucesivo). De los 197 participantes, el 53\% sólo consumía cocaína, el 5\% sólo ATS y el 18\% cocaína y ATS; el 24\% restante únicamente se inyectaba opiáceos. En comparación con las PWID que únicamente se inyectaban opioides, las PWID que consumían paralelamente estimulantes tenían puntuaciones medias más altas en el RAB de riesgo de drogas: cocaína, $b=2.84$ puntos (intervalo de confianza [IC] del 95\%

Raagini Jawa

Raagini.jawa@bmc.org

1 Section of Infectious Diseases, Boston Medical Center, 801 Massachusetts Ave, 2nd Floor, Boston, MA 02118, USA

2 Boston University School of Public Health, Boston, MA, USA

3 Behavioral Medicine and Addictions Research, Butler Hospital, Providence, RI, USA

4 Division of General Internal Medicine, Center for Research On Health Care, University of Pittsburgh, Pittsburgh, PA, USA

5 Center for Integrated Health Care Research, Kaiser Permanente Honolulu, Honolulu, HI, USA

6 Boston University School of Medicine, Boston, MA, USA 
1.01; 4.67); ATS, $b=3.43$ puntos (IC del 95\% 1.29; 5.57). En comparación con las PWID que únicamente se inyectaban opioides, el co-consumo de cocaína se relacionó con puntuaciones más altas en la RAB en el sexo (1.06 puntos, IC del 95\% $0.32 ; 1.79)$. En general, se encontró una asociación significativa entre el co-consumo de estimulantes y las puntuaciones más altas de riesgo sexual y de drogas frente al VIH.

\section{Introduction}

Despite advances in HIV testing, prevention, and treatment, people who inject drugs (PWID) remain at significant risk for HIV acquisition, accounting for 1 in 10 new HIV infections [1]. For PWID, HIV acquisition is mediated by both injection drug and sexual risk behaviors [2-4]. These risks for HIV have been noted among PWID with opioid use alone [5]; however, more recently, polydrug use with stimulants and opioids has become increasingly common. From 2015 to 2017, opioid overdose deaths involving stimulants have doubled [6] and as of 2019, nearly $83.8 \%$ of PWID who died of an overdose used stimulants in combination with opioids [7]. Polydrug use has risen even more dramatically throughout the COVID-19 pandemic [8,9].

While co-use of stimulants with opioids is often regarded as "risky" practice, PWID perceive it as a reasonable practice [10] in promoting positive psychoactive effects and opioid intoxication, modulating the severity of opioid withdrawal, and reducing over-excitability from stimulant use $[10,11]$. While opioid and cocaine co-use has been common for years (e.g., speedball injection), co-use of opioids with amphetamine-type stimulants (ATS) like methamphetamine have recently increased [11]. Unlike cocaine, illicit ATS tend to be less expensive, locally supplied, and have longer lasting stimulant effects [12]. Given the inherent difference in stimulant and opioid pharmacology, varying methods of drug preparation, typical frequency of injection, and psychoactive impact, there is a mounting body of evidence that shows that people with opioid and stimulant co-use have differential infectious disease acquisition compared to those PWID who only use opioids [13-16]. While this unique population of PWID has been at significant risk for fatal overdose and infections related to drug use including HIV, little is known about the magnitude of its impact on their HIV risk behaviors.

The risk of HIV acquisition among people who inject opioids is well established and demonstrated by multiple recent HIV outbreaks in the U.S. Particularly in areas where fentanyl is combined with heroin and stimulant use was prevalent, these HIV outbreaks were associated with high frequency of daily injections and sharing of injection equipment [5, 17]. Opioid use, especially injection opioid use among men who have sex with men (MSM), is associated with engaging in increased unprotected sexual intercourse and other higher sex risk practices for HIV [18]. Furthermore, stimulant use alone is associated with increased sexual and injection risk behaviors for HIV [19-26]. Individuals who injected stimulants are more likely to engage in higher risk drug practices including needle sharing [27] and increased injection frequency [10]. In the context of MSM and other sexual minorities, all routes of stimulant use are associated with unprotected anal intercourse with casual partners and a greater number of sexual partners [24, 28-32], and methamphetamine use among MSM has been reported to be the greatest risk factor for HIV seroconversion [33, 34]. Literature suggests that opioid use or stimulant use alone independently are associated with greater impulsivity and sensation seeking $[35,36]$ which may cause PWID to engage in higher risk sexual and injection drug risk behaviors [27, 37].

With the evolving drug epidemic and rising rates of stimulant and opioid co-use, it is crucial to understand its impact on behaviors that increase the risk for HIV. Doing so may help inform public health programs to target interventions towards the most significant risk behaviors in order to minimize risk of HIV acquisition for PWID. In this study, we evaluated distinct drug injection practices and sexual risk behaviors for HIV among PWID who use opioids as compared to those who co-use opioids and stimulants. We hypothesized that PWID who co-used opioids and stimulants have greater HIV associated risk behaviors as compared to PWID using opioids alone.

\section{Methods}

\section{Study Design}

We conducted a cross sectional analysis of baseline survey data from the Skin and Needle Hygiene Intervention (SKIN) clinical trial [38] to explore the association between HIV risk behaviors and stimulant co-use versus injection opioid use alone.

\section{Study Participants}

Participants were PWID hospitalized at a large, academic safety-net hospital in Boston and were recruited for a randomized trial aimed at reducing skin infections from January 2014 to June 2018 [38]. Enrolled participants self-reported injection drug use at least three times in the week prior to hospitalization, completed a $90-\mathrm{min}$ baseline questionnaire, and were randomized to either the motivational, educational skin hygiene intervention or 
assessment-only arm. For this analysis our $n=201$. We included all SKIN trial participants who primarily injected opioids and excluded participants who were HIV-positive by self-report so as to understand risk behaviors among PWID at risk of HIV acquisition. Item specific missing data on impulsivity scores reduced the sample to 197 . The study specifics have been previously published [38].

\section{Exposure}

From baseline enrollment, we assessed two different sub-groups of individuals who co-used opioids with: (1) cocaine, (2) ATS and compared these with persons who only injected opioids. These sub-groups were derived using individuals who co-used stimulants (irrespective of ingestion route) in the past 90 days based on the Addiction Severity Index (ASI) Drug Module, a semi-structured interview that quantifies the type of substances used in the past 90 days, including the route of administration (i.e., intravenous injection, non-intravenous injection, oral, nasal, smoking) [39]. Stimulants were defined as cocaine, which includes freebase, crack, powder and ATS, which includes crystal meth, Ritalin, speed dexedrine, crank, black beauties, and ice.

\section{Outcome}

We used the Risk Assessment Battery (RAB), a standardized and validated questionnaire to define HIV risk. The RAB was designed to elicit past 3-month drug use behaviors, with higher scores on both sex and injection drug-use sub-scales indicating greater levels of HIV risktaking [40]. The primary outcomes of interest were RAB drug and sex sub-scale scores. The 8 -item drug risk subscale (value range 0-22) includes questions such as the frequency of injection drug-use, sharing of needles and works, and the number of recent visits to a shooting gallery. The 9-item sex risk sub-scale (value range 0-18) includes questions involving the number of sexual partners, sexual orientation, frequency of condom use, and the number of times sex was exchanged for drugs or money. The composite RAB score (drug plus sex sub-scale scores) has been correlated with HIV sero-status and seroconversion [40]. The RAB has high test-retest reliability and discriminant validity in differentiating between different drug-use patterns, and predictive validity in identifying persons who have HIV seroconversion. We use the term 'drug risk' throughout the manuscript to describe HIV drug risk behaviors as defined by the RAB drug risk subscale. Similarly, we use the term 'sex risk' to describe the
HIV sex risk behaviors as defined by the RAB sex risk sub-scale.

\section{Covariates}

We analyzed covariates of age, gender, race, ethnicity, housing status, impulsivity score; these were chosen based on their association with HIV risk behaviors. Impulsivity was measured using a 5-item scale developed by Cherpitel that assesses the frequency of various impulsive behaviors $($ Cronbach's alpha $=0.80)$ [41].

\section{Analytical Methods}

We provide descriptive statistics of the sample and used multiple linear regression to estimate the adjusted association of the RAB drug risk and sex risk scores with co-use of stimulants. For each outcome we estimated three models so as to understand the independent impact that type of stimulant co-used had on RAB drug and sex risk scores. Model I excluded ATS use, Model II excluded cocaine use, and Model III included both cocaine use and ATS use. Covariates included in all models were age, gender (male, female), race (white, Black, Asian, American Indian, Pacific Islander, Mixed, other), ethnicity (Latinx), homelessness (spent any nights on the street or shelter in the past 90-days), and impulsivity scores. As an additional measure of effect size we reported partial eta ${ }^{2}$ which gives the proportion of residual variance uniquely accounted for by cocaine and ATS use in each model. Additionally, we tested the first order cocaine by ATS use interaction to determine if combined use of both had synergistic or antagonistic effects on risk. Tests of significance and 95\% confidence interval (CI) estimates were based on the Huber-White variance estimator, which is robust to heteroscedasticity. The study was approved by the Boston University Medical Center Institutional Review Board.

\section{Results}

Our cohort included 197 participants who primarily injected opioids and were 36.8 years old $( \pm 10.3), 56.4 \%$ male, $63.5 \%$ white, $16.2 \%$ Latinx, and $59.4 \%$ who had experienced homelessness in the 90-days prior to enrollment (Table 1). Approximately $72.6 \%$ of participants reported past 90 -day cocaine use, with $25.9( \pm 31.0)$ mean days of use. Among those who co-used cocaine, 38.5\% reported that they primarily injected. In the entire sample, forty-eight participants (24.4\%) reported past 90-day ATS use and mean days of use was $5.60( \pm 18.8)$ days. Among those who co-use ATS, $66.7 \%$ reported that they primarily injected. Among the entire cohort, 43 (23.8\%) didn't 
Table 1 Baseline characteristics of cohort of hospitalized HIVnegative people who inject drugs $(\mathrm{n}=197)$

\begin{tabular}{|c|c|c|c|c|c|c|}
\hline & $\mathrm{n}(\%)$ & Mean & SD & Median & Min & $\operatorname{Max}$ \\
\hline Years age & & 36.8 & 10.3 & 34 & 19 & 62 \\
\hline Sex (male) & $111(56.4 \%)$ & & & & & \\
\hline Race (white) & $125(63.5 \%)$ & & & & & \\
\hline Ethnicity (Latinx) & $32(16.2 \%)$ & & & & & \\
\hline Homelessness (yes) & $117(59.4 \%)$ & & & & & \\
\hline Impulsivity Score ${ }^{\mathrm{a}}$ & & 2.99 & 0.81 & 3.2 & 1 & 4 \\
\hline Past 90 day cocaine use (yes) & $143(72.6 \%)$ & & & & & \\
\hline Days used cocaine $(0-90)$ & & 25.9 & 31.0 & 10 & 0 & 90 \\
\hline Injected cocaine (yes) & 55 & & & & & \\
\hline Past 90 day ATS use (yes) & $48(24.4 \%)$ & & & & & \\
\hline Days used ATS (0-90) & & 5.60 & 18.8 & 0 & 0 & 90 \\
\hline Injected ATS (Yes) & 32 & & & & & \\
\hline RAB drug risk & & 9.44 & 6.78 & 9 & 1 & 22 \\
\hline RAB sex risk & & 3.47 & 3.65 & 3 & 0 & 17 \\
\hline
\end{tabular}

$A T S$ amphetamine type stimulants, $R A B$ risk assessment battery, $S D$ standard deviation

${ }^{a}$ Impulsivity Score: 5 item scale developed by Cherpitel [41] use either cocaine or ATS, 106 (53.8\%) co-used cocaine but not ATS, $11(5.6 \%)$ co-used ATS but not cocaine, and $37(18.8 \%)$ co-used both cocaine and ATS in the past 90-days. PWID who injected opioids alone had mean $\mathrm{RAB}$ drug risk score of $5.98( \pm 5.88)$ and sex risk score of 2.16 ( \pm 2.20$)$ ("Appendix 1").

\section{RAB Drug Risk}

The adjusted mean RAB drug risk score was 2.84 (95\% CI $1.01 ; 4.67, \mathrm{t}=3.07, \mathrm{p}=0.002$ ) points higher among persons who reported cocaine co-use than among those who had not used cocaine in Model I (Table 2). Persons reporting ATS co-use also had significantly higher $(3.43,95 \% \mathrm{CI}$ $1.29 ; 5.57, \mathrm{t}=3.16, \mathrm{p}=0.002$ ) adjusted mean $\mathrm{RAB}$ drug risk scores than those who had not used ATS (Model II).

Table 2 Multiple linear regression of RAB drug risk score on cocaine and ATS use $(n=197)$

\begin{tabular}{|c|c|c|c|c|c|c|}
\hline & \multicolumn{2}{|l|}{ Model I ${ }^{\mathrm{a}}$} & \multicolumn{2}{|l|}{ Model II ${ }^{\mathrm{b}}$} & \multicolumn{2}{|l|}{ Model III ${ }^{\mathrm{c}}$} \\
\hline & $\mathrm{b}(95 \% \mathrm{CI})^{\mathrm{d}}$ & $\mathrm{t}(\mathrm{p}=)$ & $\mathrm{b}(95 \% \mathrm{CI})^{\mathrm{d}}$ & $\mathrm{t}(\mathrm{p}=)$ & $\mathrm{b}(95 \% \mathrm{CI})^{\mathrm{d}}$ & $\mathrm{t}(\mathrm{p}=)$ \\
\hline Current age & $0.01(-0.09 ; 0.11)$ & $0.14(0.887)$ & $0.00(-0.10 ; 0.10)$ & $0.06(0.952)$ & $0.03(-0.07 ; 0.12)$ & $0.52(0.602)$ \\
\hline Sex (male) & $-3.29(-5.17 ;-1.41)$ & $-3.46(0.001)$ & $-3.36(-5.27 ;-1.45)$ & $-3.47(0.001)$ & $-3.37(-5.22 ;-1.51)$ & $-3.59(<0.000)$ \\
\hline Race (white) & $2.52(0.30 ; 4.73)$ & $2.24(0.026)$ & $1.71(-0.58 ; 4.00)$ & $1.47(0.142)$ & $1.98(-0.28 ; 4.23)$ & $1.73(0.085)$ \\
\hline Ethnicity (Latinx) & $0.48(-2.23 ; 3.19)$ & $0.35(0.729)$ & $0.81(-1.95 ; 3.58)$ & $0.58(0.562)$ & $0.71(-2.00 ; 3.42)$ & $0.52(0.604)$ \\
\hline Homelessness & $2.78(1.00 ; 4.55)$ & $3.09(0.002)$ & $2.87(1.14 ; 4.59)$ & $3.29(0.001)$ & $2.58(0.87 ; 4.20)$ & $2.97(0.003)$ \\
\hline Impulsivity & $0.75(-0.41 ; 1.91)$ & $1.27(0.297)$ & $0.65(-0.53 ; 1.83)$ & $1.09(0.277)$ & $0.58(-0.55 ; 1.72)$ & $1.02(0.311)$ \\
\hline Used cocaine (yes) & $2.84(1.01 ; 4.67)$ & $3.07(0.002)$ & N/A & & $2.75(0.95 ; 4.55)$ & $3.01(0.003)$ \\
\hline Used ATS (yes) & N/A & & $3.43(1.29 ; 5.57)$ & $3.16(0.002)$ & $3.34(1.25 ; 5.42)$ & $3.16(0.002)$ \\
\hline Constant & $3.41(-2.28 ; 9.11)$ & $1.18(0.238)$ & $5.51(0.21 ; 10.82)$ & $2.05(0.042)$ & $2.92(-2.65 ; 8.48)$ & $1.03(0.302)$ \\
\hline Model F $(\mathrm{p}=)$ & $8.70(<0.001)$ & & $8.31(<0.001)$ & & $9.15(<0.001)$ & \\
\hline Model $\mathrm{R}^{2}$ & 0.198 & & 0.208 & & 0.238 & \\
\hline $\mathrm{Eta}^{2}$ cocaine & 0.040 & & N/A & & 0.040 & \\
\hline $\mathrm{Eta}^{2} \mathrm{ATS}$ & N/A & & 0.050 & & 0.050 & \\
\hline
\end{tabular}

$A T S$ amphetamine type stimulants, $C I$ confidence interval, $R A B$ risk assessment battery, $S D$ standard deviation

${ }^{a}$ Model I excluded ATS use

${ }^{\mathrm{b}}$ Model II excluded cocaine use

${ }^{\mathrm{c}}$ Model III included both cocaine and ATS use

${ }^{\mathrm{d}} 95 \%$ confidence interval estimates and tests of significance were based on the robust Huber-White variance estimator 
When simultaneously included in the model (Model III) both cocaine $(2.75,95 \%$ CI $0.95 ; 4.55, \mathrm{t}=3.01, \mathrm{p}=0.003)$ and ATS $(3.34,95 \%$ CI $1.25 ; 5.42, \mathrm{t}=3.16, \mathrm{p}=0.002)$ were associated significantly with higher drug risk scores. The effects of cocaine co-use and ATS co-use on drug risk scores were largely independent. The cocaine by ATS interaction effect was not significant statistically $(b=0.24,95 \% \mathrm{CI}-4.43$; $4.91, t=0.10, p=0.918)$ and the coefficients for each in Model III were only slightly attenuated when compared to the coefficients of each in Models I and II. And when rounded to the 3rd decimal, the partial eta ${ }^{2}$ statistics did not change when both cocaine and ATS were included in Model III. Males had significantly lower drug risk scores than females, whites had significantly higher (not significant in Model II) drug risk scores than racial minorities, and persons who had ever experienced homelessness had significantly higher drug risk scores than those who had never experienced homelessness.

\section{RAB Sex Risk}

Co-use of cocaine was positively and significantly associated with the adjusted mean RAB sex risk score in both Model I $(1.06,95 \%$ CI $0.32 ; 1.79, \mathrm{t}=2.83, \mathrm{p}=0.005)$ and Model III $(1.05,95 \%$ CI $0.31 ; 1.78, \mathrm{t}=2.82, \mathrm{p}=0.005)$ (Table 3$)$. ATS co-use was not associated significantly with sex risk scores and the substantive magnitude of the adjusted association was small. The first order cocaine by ATS interaction effect was not statistically significant $(b=0.61,95 \% \mathrm{CI}-1.64$; $2.85, \mathrm{t}=0.53, \mathrm{p}=0.593)$. Partial eta ${ }^{2}$ decreased only very slightly when ATS use was included in the model. Males had significantly lower sex risk scores than females. Sex risk scores were not significantly associated with other covariates included in the regression models.

\section{Discussion}

In this study of hospitalized PWID who injected opioids, we found that those who co-used stimulants in the past 90 days had significantly higher RAB drug and sex HIV risk scores as compared to those who used opioids alone, controlling for important covariates. Our study adds to a growing body of literature around clinical outcomes for stimulant co-use with opioids and supports the hypothesis that this population of PWID may be engaging in higher risk behaviors for HIV than those who inject opioids alone. Our findings are novel in that we found that the type of stimulants co-used conferred a differential impact on RAB drug risk scores.

One international study suggested an association of increased injection drug risk when PWID co-injected opioids and any type of stimulants [42]. Results presented here expand on this prior research as we found that the type of stimulant co-used matters. Based on our results of Model I and II, the type of stimulant co-used each conferred significantly different and largely independent effects on drug

Table 3 Multiple linear regression of RAB sex risk score on cocaine and ATS use $(n=197)$

\begin{tabular}{|c|c|c|c|c|c|c|}
\hline & \multicolumn{2}{|l|}{ Model I ${ }^{\mathrm{a}}$} & \multicolumn{2}{|l|}{ Model $\mathrm{II}^{\mathrm{b}}$} & \multicolumn{2}{|l|}{ Model III ${ }^{\mathrm{c}}$} \\
\hline & $\mathrm{b}(95 \% \mathrm{CI})^{\mathrm{d}}$ & $\mathrm{t}(\mathrm{p}=)$ & $\mathrm{b}(95 \% \mathrm{CI})^{\mathrm{d}}$ & $\mathrm{t}(\mathrm{p}=)$ & $\mathrm{b}(95 \% \mathrm{CI})^{\mathrm{d}}$ & $\mathrm{t}(\mathrm{p}=)$ \\
\hline Current age & $-0.04(-0.08 ; 0.01)$ & $-1.60(0.112)$ & $-0.04(-0.09 ; 0.00)$ & $-1.87(0.063)$ & $-0.04(-0.08 ; 0.02)$ & $-1.47(0.142)$ \\
\hline Sex (male) & $\begin{array}{l}-3.85(-4.83 \\
-2.87)\end{array}$ & $-7.72(<0.001)$ & $\begin{array}{l}-3.85(-4.85 \\
-2.86)\end{array}$ & $-7.67(<0.001)$ & $\begin{array}{l}-3.86(-4.84 \\
-2.86)\end{array}$ & $-7.69(<0.001)$ \\
\hline Race (white) & $0.61(-0.42 ; 1.64)$ & $1.17(0.243)$ & $0.47(-0.60 ; 1.53)$ & $0.86(0.390)$ & $0.57(-0.48 ; 1.61)$ & $1.07(0.287)$ \\
\hline Ethnicity (Latinx) & $0.51(-0.49 ; 1.51)$ & $1.00(0.319)$ & $0.56(-0.48 ; 1.61)$ & $1.06(0.289)$ & $0.53(-0.49 ; 1.54)$ & $1.02(0.307)$ \\
\hline Homelessness & $0.72(-0.12 ; 1.57)$ & $1.70(0.091)$ & $0.82(-0.03 ; 0.78)$ & $1.90(0.059)$ & $0.71(-0.13 ; 1.55)$ & $1.67(0.097)$ \\
\hline Impulsivity & $0.29(-0.18 ; 0.76)$ & $1.22(0.225)$ & $0.30(-0.18 ; 0.78)$ & $1.24(0.218)$ & $0.28(-0.21 ; 0.76)$ & $1.13(0.260)$ \\
\hline Used cocaine (yes) & $1.06(0.32 ; 1.79)$ & $2.83(0.005)$ & N/A & & $1.05(0.31 ; 1.78)$ & $2.82(0.005)$ \\
\hline Used ATS (yes) & N/A & & $0.31(-0.90 ; 1.51)$ & $0.50(0.617)$ & $0.27(-0.91 ; 1.46)$ & $0.45(0.652)$ \\
\hline Constant & $4.45(1.72 ; 7.19)$ & $3.21(0.002)$ & $5.40(2.79 ; 8.01)$ & $4.08(<0.000)$ & $4.41(1.67 ; 7.16)$ & $3.17(0.002)$ \\
\hline Model F $(p=)$ & $13.68(<0.001)$ & & $13.40(<0.001)$ & & $12.07(<0.001)$ & \\
\hline Model $\mathrm{R}^{2}$ & 0.388 & & 0.373 & & 0.389 & \\
\hline $\mathrm{Eta}^{2}$ cocaine & 0.026 & & N/A & & 0.025 & \\
\hline $\mathrm{Eta}^{2} \mathrm{ATS}$ & N/A & & 0.002 & & 0.001 & \\
\hline
\end{tabular}

$A T S$ amphetamine type stimulants, $C I$ confidence interval, $R A B$ risk assessment battery, $S D$ standard deviation

${ }^{a}$ Model I excluded ATS use

${ }^{\mathrm{b}}$ Model II excluded cocaine use

${ }^{\mathrm{c}}$ Model III included both cocaine and ATS use

${ }^{\mathrm{d}} 95 \%$ Confidence interval estimates and tests of significance were based on the robust Huber-White variance estimator 
risk scores. Even though all stimulants have similar sympathomimetic effects, individually, cocaine and ATS have quite distinct patterns of use, duration of action, and physiological intoxication syndromes which could explain differential impact on drug risk scores. Unlike cocaine, PWID who use ATS experience intoxication syndromes that can last for days, often with post-use psychotic features [43], and prolonged motor and cognitive impairment [44] which may impact their ability to engage in safer injection drug practices. Furthermore, while studies have shown that both cocaine and ATS have an impact on impulsivity and behavioral disinhibition [36, 45], ATS-induced sleep deprivation could further exacerbate PWID's drug risk taking behaviors. Though our study was underpowered to stratify PWID based on the route of administration of drugs, we suspect that those who co-inject stimulants may be engaging in greater injection drug risks behaviors.

Our findings also suggest that not only does the type of stimulant co-used have independent impact on drug risk, but if PWID co-use multiple types of stimulants with opioids they may further increase their drug risk. PWID who co-use multiple stimulants along with opioids may have a more severe addictive disorder with polydrug use pattern potentiating further impulsive behavior or have an underlying stimulant use disorder. While there is emerging data on medications to reduce stimulant cravings [46], there is not an evidence-based highly effective medication for treatment to date [20] and continued stimulant use has been shown to place PWID at risk for ongoing opioid use and disengagement from opioid use disorder treatment [47, 48]. Thus, stimulant co-users, particularly ones who co-use multiple stimulants, may be increasingly vulnerable to engage in higher drug risk behaviors and be at risk for HIV infection $[49,50]$.

In light of the rapidly growing population of PWID who co-use stimulants with opioids, our results suggest an urgency to target harm reduction strategies to reduce drug risk behaviors so as to minimize the risk of future HIV outbreaks. When people who inject opioids, particularly ones who co-use stimulants, access the healthcare system, it is an opportunity to screen this vulnerable population for HIV risk behaviors and engage in HIV prevention. At syringe service programs [51] or during an acute hospitalization (such as in our cohort) clinicians can identify PWID who are co-using stimulants with opioids as being at higher risk of engaging in HIV drug and sex risk behaviors and, thus, prioritize preventive harm reduction strategies such as HIV screenings or prescribing pre-exposure prophylaxis.

Consistent with previous studies, we found that cocaine co-use among our cohort was associated with a greater sex risk compared to when no cocaine was co-used [52]. Interestingly, our models did not show a significant association of ATS co-use with sex risk scores. Given ATS impact on increasing libido and impulsivity, our findings stand in contrast to numerous studies among PWID and MSM which have shown that ATS use leads to higher risk sexual behaviors such as unprotected intercourse or having multiple sexual partners [21, 53-56] and trading sex for drugs [57]. Our cohort was not primarily MSM; further, a minority of our participants co-used ATS with low frequency over the 90 day recall period which may have contributed to differences in our findings from previous work.

\section{Limitations}

Some limitations warrant discussion. First, the sample size was limited to PWID hospitalized for an acute medical condition who, therefore, may represent a particularly high-risk group not representative of PWID in the community. In addition, the setting for the study was an urban, safety-net hospital, so findings may not be generalizable to rural/suburban PWID, or to out-of-treatment PWID who have not been hospitalized. Second, opioid and stimulant drug use and other risk behaviors are based on participant self-report, though previous literature has suggested that PWID provide reliable and valid responses [58, 59]. Third, given differential geographic drug use trends, our cohort had a low prevalence of PWID who co-used ATS which may have impacted our power to detect group differences. Fourth, we did not enroll non-English speaking patients in the study, although several of the participants did speak English as a second language at a level sufficient to provide informed consent and complete study assessments. Fifth, the ASI asks about amphetamine or methamphetamine use, but participants did not specify illicit or licit use with prescription stimulants, thus we are unable to report specific breakdown of the types of ATS co-used. Lastly, due to the manner in which the baseline survey questions were designed, we were unable to identify participants who only used non-injection routes of opioids. Even though the RAB drug risk score would not be applicable to this population, further research is needed to evaluate their HIV sex risk factors associated with stimulant co-use.

\section{Conclusions}

While we have seen that rising rates of polysubstance use have led to increased fatal overdoses over the past several years, our results suggest that PWID who co-use stimulants with opioids may be engaging in significant HIV risk behaviors as well. Healthcare resources ought to target increased HIV screening, access to HIV pre-exposure prophylaxis, and developing effective harm reduction risk services addressing both sexual and drug risk behaviors with attention to 
persons who co-use opioids and stimulants, and such prevention schemes could well be initiated in hospital settings.

\section{Appendix 1 Mean RAB drug and sex risk scores of hospitalized cohort of HIV-negative people who inject opioids $(n=197)$}

\begin{tabular}{lcc}
\hline $\begin{array}{l}\text { Participant patterns of cocaine } \\
\text { and ATS use }\end{array}$ & RAB drug $( \pm$ SD) & RAB sex $( \pm$ SD) \\
\hline $\begin{array}{l}\text { No co-use (opioids only; } \\
\mathrm{n}=43)\end{array}$ & $5.98( \pm 5.88)$ & $2.16( \pm 2.20)$ \\
$\begin{array}{l}\text { Co-used cocaine only } \\
(\mathrm{n}=106)\end{array}$ & $9.29( \pm 6.69)$ & $3.48( \pm 3.95)$ \\
$\begin{array}{l}\text { Co-used ATS only }(\mathrm{n}=11) \\
\begin{array}{l}\text { Co-used cocaine and ATS } \\
(\mathrm{n}=37)\end{array}\end{array}$ & $10.91( \pm 5.63)$ & $3.27( \pm 2.00)$ \\
\end{tabular}

$A T S$ amphetamine type stimulants, $R A B$ risk assessment battery, $S D$ standard deviation

Acknowledgements Research reported in this publication was supported by the National Institute on Drug Abuse (R01DA034957 to M.D.S, B.A; K01DA051684 and DP2DA051864-01 to J.A.B; and R25DA033211 to R.J.), National Institute of Allergy and Infectious Diseases to (R25DA033211 and T32AI052074 to R.J). Neither NIDA nor NIAID had a further role in study design, in the collection, analysis and interpretation of data, or in the decision to submit the paper for publication.

Author Contributions RJ originated the study concept and drafted the manuscript. JB advised on all aspects of the study and contributed to manuscript preparation and revisions. BA conducted statistical analyses and reviewed drafts of the manuscript. MS, JML, KTP, CS advised on all aspects of the study and contributed to manuscript preparation and revisions. All authors approved the final version for publication.

Funding This study was funded by the National Institutes of Health R01DA034957. The first author was supported by the Research in Addiction Medicine Scholars (RAMS) Program, R25DA033211 and Boston University Clinical HIV/AIDS Research Training (BUCHART) Program Funded by Grant \# T32AI052074. The last author is supported by Grant \# K01DA051684, DP2DA51864.

Data Availability Not Applicable.

Code Availability Not Applicable.

\section{Declarations}

Conflict of interest The authors have no conflicts of interest to report. Data in this manuscript were collected by the Preventing Bacterial and Viral Infections among Injection Drug Users study (R01DA034957-06). We acknowledge the time and effort of all study participants.

Consent for Publication We provide consent to publish this manuscript.
Ethical Approval All study procedures were approved by the Boston University Medical Center's Institutional Review Board. Procedures involving human subjects were conducted in accordance with ethical standards of the institutional and/or national research committee and in accordance with the 1964 Helsinki Declaration and its later amendments.

Informed Consent Informed consent was obtained from all individual participants prior to survey administration.

\section{References}

1. HIV and Injection Drug Use. 2016. https://www.cdc.gov/vital signs/hiv-drug-use/index.html. Accessed 09 Sept 2020

2. Cranston K, Alpren C, John B, Dawson E, Roosevelt K, Burrage A, et al. Notes from the field: HIV diagnoses among persons who inject drugs-Northeastern Massachusetts, 2015-2018. MMWR Morb Mortal Wkly Rep. 2019;68(10):253-4.

3. Golden MR, Lechtenberg R, Glick SN, Dombrowski J, Duchin J, Reuer JR, et al. Outbreak of human immunodeficiency virus infection among heterosexual persons who are living homeless and inject drugs-Seattle, Washington, 2018. MMWR Morb Mortal Wkly Rep. 2019;68(15):344-9.

4. Strathdee SA, Hallett TB, Bobrova N, Rhodes T, Booth R, Abdool $\mathrm{R}$, et al. HIV and risk environment for injecting drug users: the past, present, and future. Lancet. 2010;376(9737):268-84.

5. Alpren C, Dawson EL, John B, Cranston K, Panneer N, Fukuda HD, et al. Opioid use fueling HIV transmission in an urban setting: an outbreak of HIV infection among people who inject drugs-Massachusetts, 2015-2018. Am J Public Health. 2020;110(1):37-44.

6. Kariisa M, Scholl L, Wilson N, Seth P, Hoots B. Drug overdose deaths involving cocaine and psychostimulants with abuse potential-United States, 2003-2017. MMWR Morb Mortal Wkly Rep. 2019;68(17):388-95.

7. O'Donnell J, Gladden RM, Mattson CL, Hunter CT, Davis NL. Vital signs: characteristics of drug overdose deaths involving opioids and stimulants-24 states and the district of Columbia, January-June 2019. MMWR Morb Mortal Wkly Rep. 2020;69(35):1189-97.

8. Wainwright JJ, Mikre M, Whitley P, Dawson E, Huskey A, Lukowiak A, et al. Analysis of drug test results before and after the us declaration of a national emergency concerning the COVID-19 outbreak. JAMA. 2020. https://doi.org/10.1001/jama. 2020.17694 .

9. Niles JK, Gudin J, Radcliff J, Kaufman HW. The opioid epidemic within the COVID-19 pandemic: drug testing in 2020. Popul Health Manage. 2020. https://doi.org/10.1089/pop.2020.0230.

10. Palmer A, Scott N, Dietze P, Higgs P. Motivations for crystal methamphetamine-opioid co-injection/co-use amongst community-recruited people who inject drugs: a qualitative study. Harm Reduct J. 2020;17(1):14.

11. Ellis MS, Kasper ZA, Cicero TJ. Twin epidemics: the surging rise of methamphetamine use in chronic opioid users. Drug Alcohol Depend. 2018;193:14-20.

12. United Nations International Drug Control Programme. Amphetamine-type stimulants: a global review/prepared by UNDCP at the request of the Commission on Narcotic Drugs. UNDCP Technical Series. Vienna; 1996

13. Bartholomew TS, Tookes HE, Bullock C, Onugha J, Forrest DW, Feaster DJ. Examining risk behavior and syringe coverage among 
people who inject drugs accessing a syringe services program: a latent class analysis. Int J Drug Policy. 2020;78:102716.

14. Barocas JA, Wang J, Marshall BDL, LaRochelle MR, Bettano A, Bernson D, et al. Sociodemographic factors and social determinants associated with toxicology confirmed polysubstance opioidrelated deaths. Drug Alcohol Depend. 2019;200:59-63.

15. Al-Tayyib A, Koester S, Langegger S, Raville L. Heroin and methamphetamine injection: an emerging drug use pattern. Subst Use Misuse. 2017;52(8):1051-8.

16 Serota DP, Bartholomew TS, Tookes HE. Evaluating differences in opioid and stimulant use-associated infectious disease hospitalizations in Florida, 2016-2017. Clin Infect Dis. 2020. https:// doi.org/10.1093/cid/ciaa1278.

17. Ciccarone D, Ondocsin J, Mars SG. Heroin uncertainties: exploring users' perceptions of fentanyl-adulterated and -substituted "heroin.” Int J Drug Policy. 2017;46:146-55.

18. Zule WA, Oramasionwu C, Evon D, Hino S, Doherty IA, Bobashev GV, et al. Event-level analyses of sex-risk and injection-risk behaviors among nonmedical prescription opioid users. Am J Drug Alcohol Abuse. 2016;42(6):689-97.

19. Crooks D, Tsui J, Anderson B, Dossabhoy S, Herman D, Liebschutz JM, et al. Differential risk factors for HIV drug and sex risk-taking among non-treatment-seeking hospitalized injection drug users. AIDS Behav. 2015;19(3):405-11.

20. Farrell M, Martin NK, Stockings E, Borquez A, Cepeda JA, Degenhardt L, et al. Responding to global stimulant use: challenges and opportunities. Lancet. 2019;394(10209):1652-67.

21. Jia ZJ, Yan SY, Bao YP, Lian Z, Zhang HR, Liu ZM. Sexual behavior differences between amphetamine-type stimulants users and heroin users. J Addict Med. 2013;7(6):422-7.

22. Rawson RA, Washton A, Domier CP, Reiber C. Drugs and sexual effects: role of drug type and gender. J Subst Abuse Treat. 2002;22(2):103-8.

23. Semple SJ, Strathdee SA, Zians J, Patterson TL. Social and behavioral characteristics of HIV-positive MSM who trade sex for methamphetamine. Am J Drug Alcohol Abuse. 2010;36(6):325-31.

24. Marshall BD, Wood E, Shoveller JA, Patterson TL, Montaner JS, Kerr T. Pathways to HIV risk and vulnerability among lesbian, gay, bisexual, and transgendered methamphetamine users: a multicohort gender-based analysis. BMC Public Health. 2011;11:20.

25. Shannon K, Strathdee S, Shoveller J, Zhang R, Montaner J, Tyndall M. Crystal methamphetamine use among female street-based sex workers: moving beyond individual-focused interventions. Drug Alcohol Depend. 2011;113(1):76-81.

26. Volkow ND, Wang GJ, Fowler JS, Telang F, Jayne M, Wong C. Stimulant-induced enhanced sexual desire as a potential contributing factor in HIV transmission. Am J Psychiatry. 2007;164(1):157-60.

27. Martin M, Vanichseni S, Suntharasamai P, Mock PA, van Griensven F, Pitisuttithum P, et al. Drug use and the risk of HIV infection amongst injection drug users participating in an HIV vaccine trial in Bangkok, 1999-2003. Int J Drug Policy. 2010;21(4):296-301.

28. Nakamura N, Mausbach BT, Ulibarri MD, Semple SJ, Patterson TL. Methamphetamine use, attitudes about condoms, and sexual risk behavior among HIV-positive men who have sex with men. Arch Sex Behav. 2011;40(2):267-72.

29. Rawstorne P, Digiusto E, Worth H, Zablotska I. Associations between crystal methamphetamine use and potentially unsafe sexual activity among gay men in Australia. Arch Sex Behav. 2007;36(5):646-54.

30. Buchacz K, McFarland W, Kellogg TA, Loeb L, Holmberg SD, Dilley J, et al. Amphetamine use is associated with increased HIV incidence among men who have sex with men in San Francisco. AIDS. 2005;19(13):1423-4.

31. Plankey MW, Ostrow DG, Stall R, Cox C, Li X, Peck JA, et al. The relationship between methamphetamine and popper use and risk of HIV seroconversion in the multicenter AIDS cohort study. J Acquir Immune Defic Syndr. 2007;45(1):85-92.

32. Carey JW, Mejia R, Bingham T, Ciesielski C, Gelaude D, Herbst $\mathrm{JH}$, et al. Drug use, high-risk sex behaviors, and increased risk for recent HIV infection among men who have sex with men in Chicago and Los Angeles. AIDS Behav. 2009;13(6):1084-96.

33. Grov C, Westmoreland D, Morrison C, Carrico AW, Nash D. The crisis we are not talking about: one-in-three annual HIV seroconversions among sexual and gender minorities were persistent methamphetamine users. J Acquir Immune Defic Syndr. 2020;85(3):272-9.

34. Semple SJ, Zians J, Grant I, Patterson TL. Methamphetamine use, impulsivity, and sexual risk behavior among HIV-positive men who have sex with men. J Addict Dis. 2006;25(4):105-14.

35. Verdejo-Garcia AJ, Perales JC, Perez-Garcia M. Cognitive impulsivity in cocaine and heroin polysubstance abusers. Addict Behav. 2007;32(5):950-66.

36. Nielsen DA, Ho A, Bahl A, Varma P, Kellogg S, Borg L, et al. Former heroin addicts with or without a history of cocaine dependence are more impulsive than controls. Drug Alcohol Depend. 2012;124(1-2):113-20.

37. Paydary K, MahinTorabi S, SeyedAlinaghi S, Noori M, Noroozi $\mathrm{A}$, Ameri S, et al. Impulsivity, sensation seeking, and risk-taking behaviors among HIV-positive and HIV-negative heroin dependent persons. AIDS Res Treat. 2016;2016:5323256.

38 Stein MD, Phillips KT, Herman DS, Keosaian J, Stewart C, Anderson BJ, et al. Skin-cleaning among hospitalized people who inject drugs: a randomized controlled trial. Addiction. 2020. https://doi.org/10.1111/add.15236.

39. McLellan AT, Kushner H, Metzger D, Peters R, Smith I, Grissom $\mathrm{G}$, et al. The fifth edition of the addiction severity index. J Subst Abuse Treat. 1992;9(3):199-213.

40. Navaline HA, Snider EC, Petro CJ, Tobin D, Metzger D, Alterman AI, et al. Preparations for AIDS vaccine trials. An automated version of the risk assessment battery (RAB): enhancing the assessment of risk behaviors. AIDS Res Hum Retrovir. 1994;10(Suppl 2):S281-3.

41. Cherpitel CJ. Alcohol, injury, and risk-taking behavior: data from a national sample. Alcohol Clin Exp Res. 1993;17(4):762-6.

42. Tavitian-Exley I, Boily MC, Heimer R, Uuskula A, Levina O, Maheu-Giroux M. Polydrug use and heterogeneity in HIV risk among people who inject drugs in Estonia and Russia: a latent class analysis. AIDS Behav. 2018;22(4):1329-40.

43. Akindipe T, Wilson D, Stein DJ. Psychiatric disorders in individuals with methamphetamine dependence: prevalence and risk factors. Metab Brain Dis. 2014;29(2):351-7.

44. Volkow ND, Chang L, Wang GJ, Fowler JS, Leonido-Yee M, Franceschi D, et al. Association of dopamine transporter reduction with psychomotor impairment in methamphetamine abusers. Am J Psychiatry. 2001;158(3):377-82.

45. Semple SJ, Zians J, Grant I, Patterson TL. Impulsivity and methamphetamine use. J Subst Abuse Treat. 2005;29(2):85-93.

46. Trivedi MH, Walker R, Ling W, Dela Cruz A, Sharma G, Carmody $\mathrm{T}$, et al. Bupropion and naltrexone in methamphetamine use disorder. N Engl J Med. 2021;384(2):140-53.

47. Wang L, Min JE, Krebs E, Evans E, Huang D, Liu L, et al. Polydrug use and its association with drug treatment outcomes among primary heroin, methamphetamine, and cocaine users. Int J Drug Policy. 2017;49:32-40.

48. DeMaria PA Jr, Sterling R, Weinstein SP. The effect of stimulant and sedative use on treatment outcome of patients admitted to methadone maintenance treatment. Am J Addict. 2000;9(2):145-53.

49. Bull-Otterson L, Huang YA, Zhu W, King H, Edlin BR, Hoover $\mathrm{KW}$. Human immunodeficiency virus and hepatitis $C$ virus 
infection testing among commercially insured persons who inject drugs, United States, 2010-2017. J Infect Dis. 2020;222(6):940-7.

50. Cooley LA, Wejnert C, Spiller MW, Broz D, Paz-Bailey G, Group Ns. Low HIV testing among persons who inject drugs-National HIV Behavioral Surveillance, 20 U.S. cities, 2012. Drug Alcohol Depend. 2016;165:270-4.

51. Jo Y, Bartholomew TS, Doblecki-Lewis S, Rodriguez A, Forrest DW, Tomita-Barber J, et al. Interest in linkage to PrEP among people who inject drugs accessing syringe services; Miami, Florida. PLoS ONE. 2020;15(4):e0231424.

52. Hayaki J, Anderson B, Stein M. Sexual risk behaviors among substance users: relationship to impulsivity. Psychol Addict Behav. 2006;20(3):328-32.

53. Nerlander LMC, Hoots BE, Bradley H, Broz D, Thorson A, Paz-Bailey G, et al. HIV infection among MSM who inject methamphetamine in 8 US cities. Drug Alcohol Depend. 2018;190:216-23.

54. Feelemyer J, Duong Thi H, Khue Pham M, Hoang Thi G, ThiTuyetThanh N, Thi Hai Oanh K, et al. Increased methamphetamine use among persons who inject drugs in Hai Phong, Vietnam, and the association with injection and sexual risk behaviors. J Psychoact Drugs. 2018;50(5):382-9.

55. McKetin R, Lubman DI, Baker A, Dawe S, Ross J, Mattick $\mathrm{RP}$, et al. The relationship between methamphetamine use and heterosexual behaviour: evidence from a prospective longitudinal study. Addiction. 2018;113(7):1276-85.

56. Kral AH, Lorvick J, Martinez A, Lewis MA, Orr WA, Anderson R, et al. HIV prevalence and risk among heterosexual methamphetamine injectors in California. Subst Use Misuse. 2011;46(9):1081-9.

57. Semple SJ, Strathdee SA, Zians J, Patterson TL. Correlates of trading sex for methamphetamine in a sample of HIV-negative heterosexual methamphetamine users. J Psychoact Drugs. 2011;43(2):79-88.

58. De Irala J, Bigelow C, McCusker J, Hindin R, Zheng L. Reliability of self-reported human immunodeficiency virus risk behaviors in a residential drug treatment population. Am J Epidemiol. 1996;143(7):725-32.

59. Latkin CA, Vlahov D. Socially desirable response tendency as a correlate of accuracy of self-reported HIV serostatus for HIV seropositive injection drug users. Addiction. 1998;93(8):1191-7.

Publisher's Note Springer Nature remains neutral with regard to jurisdictional claims in published maps and institutional affiliations. 